\title{
Outer membrane phospholipase A's roles in Helicobacter pylori acid adaptation
}

\author{
Hilde S. Vollan ${ }^{1,2^{*}}$ (D) Tone Tannæs ${ }^{1}$, Dominique A. Caugant ${ }^{2,3}$, Gert Vriend ${ }^{4}$ and Geir Bukholm ${ }^{2,5}$
}

\begin{abstract}
Background: The $\mathrm{pH}$ of the human gastric mucosa varies around 2.5 so that only bacteria with strong acidic stress tolerance can colonize it. The ulcer causing Helicobacter pylori thrives in the gastric mucosa. We analyse the roles of the key outer membrane protein OMPLA in its roles in acid tolerance.

Results: The homology model of Helicobacter pylori outer membrane phospholipase A (OMPLA) reveals a twelve stranded $\beta$-barrel with a pore that allows molecules to pass with a diameter up to $4 \AA$. Structure based multiple sequence alignments revealed the functional roles of many amino acids, and led to the suggestion that OMPLA has multiple functions. Besides its role as phospholipase it lets urea enter and ammonium exit the periplasm. Combined with an extensive literature study, our work leads to a comprehensive model for $H$. pylori's acid tolerance. This model is based on the conversion of urea into ammonium, and it includes multiple roles for OMPLA and involves two hitherto little studied membrane channels in the OMPLA operon.

Conclusion: The three-dimensional model of OMPLA predicts a transmembrane pore that can aid H. pylori's acid tolerance through urea influx and ammonium efflux. After urea passes through OMPLA into the periplasm, it passes through the $\mathrm{pH}$-gated inner membrane channel Urel into the cytoplasm where urease hydrolyses it into $\mathrm{NH}_{3}$ and $\mathrm{CO}_{2}$. Most of the $\mathrm{NH}_{3}$ becomes $\mathrm{NH}_{4}{ }^{+}$that is likely to need an inner membrane channel to reach the periplasm. Two genes that are co-regulated with OMPLA in gastric Helicobacter operons could aid this transport. $\mathrm{The} \mathrm{NH}_{4}{ }^{+}$that might leave the cell through the OMPLA pore has been implicated in H. pylor's pathogenesis.
\end{abstract}

Keywords: Helicobacter pylori, Acid tolerance, Multifunctional OMPLA, Urea pathway

\section{Background}

H. pylori survives in the human gastric mucosa

Most bacterial proteins require a distinct $\mathrm{pH}$ to function correctly, and that optimal $\mathrm{pH}$ is usually much higher than the gastric $\mathrm{pH}$ of around 2.5 [1]. Some bacteria, however, thrive in the acidic gastric mucosa [1]. Bacterial cell walls and membranes generally are leaky [2], which would, in the stomach, rapidly lower their cytosolic $\mathrm{pH}$ if they had no effective acid stress relieve mechanism [1]. The fact that the stomach $\mathrm{pH}$ fluctuates depending on food and liquid intake [3] puts additional constraints on this acid stress relieve mechanism.

\footnotetext{
*Correspondence: h.s.vollan@medisin.uio.no

${ }^{1}$ Department of Clinical Molecular Biology (EpiGen), Division of Medicine, Akershus University Hospital and University of Oslo, PO box 28,

1478 Lørenskog, Norway

Full list of author information is available at the end of the article
}

The Helicobacter genus comprises a versatile group of species that is found in different hosts, usually colonizing the intestine, liver, or stomach [4]. They can be divided into gastric- and enterohepatic-Helicobacters, with different morphology and genetic diverse lineages [5]. H. pylori is the most prevalent species observed in the human gastric mucosa [6].

When $H$. pylori enters the acidic gastric lumen, it migrates towards the epithelial surface. The $\mathrm{pH}$ in the epithelial surface is approximately 5 , but it can fluctuate from $\mathrm{pH} 6$ to $\mathrm{pH} 1$ [1]. When H. pylori is in an acidic environment [7] $\mathrm{pH}$-dependent transcription factors like Fur, NikR, and ArsRS [8] trigger overexpression of proteins involved in motility and ammonia production. The increased expression of motility genes allows the bacteria to move away from the acidity [7], while the ammonia 
will protect the bacterium by buffering the influx of protons [1].

\section{H. pylori OMPLA implicated in colonization}

Outer membrane $(\mathrm{OM})$ proteins often are multifunctional and involved in maintaining the membrane integrity [9]. They form the first line of defence by detecting possible attacks on the membrane for which purpose many OM proteins function as signal transducers [9].

An intact $H$. pylori outer membrane phospholipase A (OMPLA) has been suggested necessary for colonization of the human gastric ventricle [10, 11]. Only $H$. pylori with intact OMPLA will survive in acidic environments in vitro, whereas phase variants with truncated OMPLA can survive at neutral $\mathrm{pH}$. At neutral $\mathrm{pH}$ the bacterial variants with intact OMPLA, have an altered lipid composition. The switch between intact and truncated OMPLA is explained by a phase-variable DNA slippage in the homopolymeric tract of the OMPLA gene, pldA [12]. Phase-variable proteins are often implicated in roles involving bacteria-environment interactions [13]. At pH 5 only $H$. pylori with intact OMPLA (OMPLA ${ }_{\mathrm{ON}^{-}}$-variant) is selected in vitro, even though the enzymatic activity at $\mathrm{pH} 5$ is turned off because the $\mathrm{pH}$ optimum for enzymatic activity is 7.

OMPLA is found in several Gram-negative species [14], and it has been suggested that OMPLA activity is triggered by diverse events, such as temperature shift or heat shock, toxin release, or membrane instability. OMPLA activity in Escherichia coli is related to loss of membrane integrity [9]. E. coli OMPLA is activated under a wide variety of conditions (e.g. membrane perturbation) by calcium-induced dimerization [15]. OMPLA may be activated under various stress conditions in different species a where phospholipase activity contributes to cell wall degradation $[9,11]$, but $H$. pylori OMPLA is not likely to be activated by acidity since the bacterium needs an intact $\mathrm{OM}$ to survive the harsh conditions in the gastric mucosa.

\section{The H. pylori acid defence mechanism hypothesis}

Intact OMPLA is required for survival of $H$. pylori in acidic environments despite the fact that OMPLA is enzymatically inactive at low $\mathrm{pH}[10,12]$. Combining these findings with experimental work on five novel isogenic pairs of OMPLA variants, and in silico analyses of OMPLA sequence and structure data augmented with a literature study, we arrive at a hypothesis for a functional mechanism for this acid protection. This hypothesis is depicted in Fig. 1, and a detailed overview of the six steps in Fig. 1 can be found in Additional file 1. All details of this model and the corroborating evidence are presented in the remainder of this article.

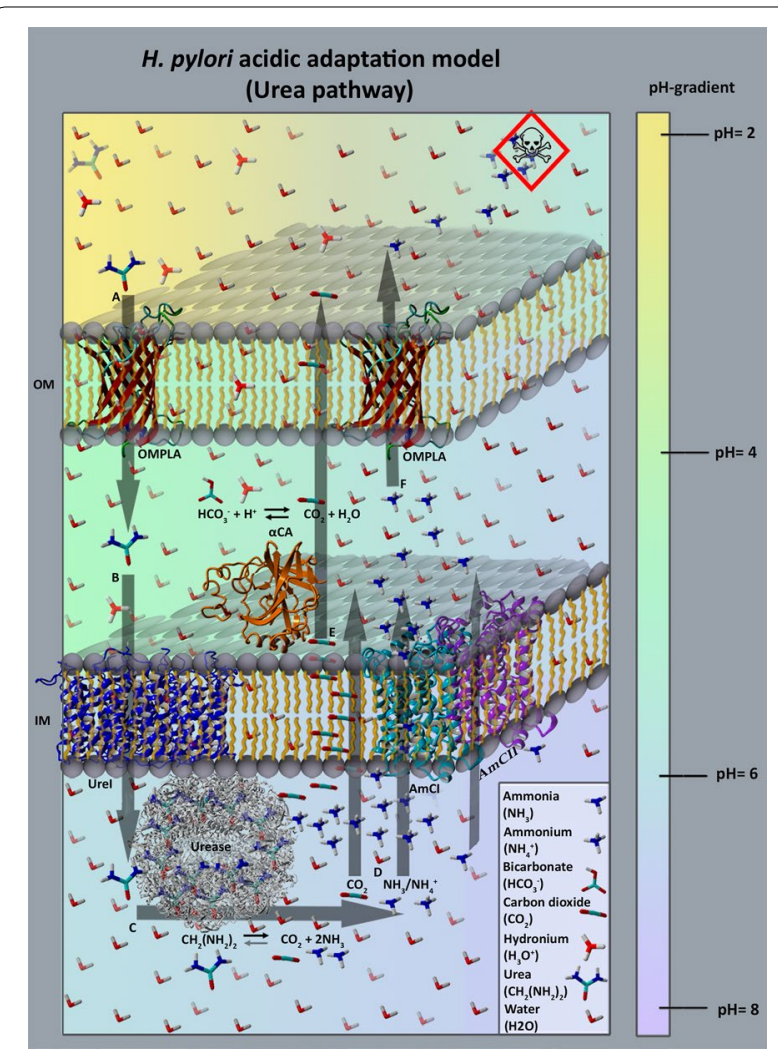

Fig. 1 H. pylori acid adaptation model. This figure schematically depicts our hypothesis on how $\mathrm{H}$. pylori uses urea in acid protection. A Urea passes through OMPLA into the periplasm simply driven by the diffusion gradient. $B$ Urea then diffuses through the protondependent inner membrane (IM) urea channel Urel to the cytoplasm. $\mathrm{C}$ Urease converts urea into $\mathrm{NH}_{3}$ and $\mathrm{CO}_{2}$. D These molecules diffuse into the periplasm. $\mathrm{CO}_{2}$ diffuses through the membrane simply following the gradient. At $\mathrm{pH}$ around $6 \mathrm{NH}_{3}$ will largely be converted to $\mathrm{NH}_{4}{ }^{+}$that passes through IM channels. A very small portion of $\mathrm{NH}_{3}$ will continuously remain and a small fraction of this $\mathrm{NH}_{3}$ will diffuse through the IM. E Most of the $\mathrm{CO}_{2}$ diffuses out of the cell, but some is converted by the periplasmic enzyme a-carbonic anhydrase (aCA) into bicarbonate. This bicarbonate forms a buffer that helps maintaining the periplasmic $\mathrm{pH}$ around 6.1. A sudden enlarged influx of protons will be buffered by this bicarbonate. $\mathrm{F} \mathrm{NH}_{4}{ }^{+}$leaves the cell mainly through OMPLA. The toxicity sign represents the damage caused by $\mathrm{NH}_{4}{ }^{+}$in the gastric mucosa. The $\mathrm{pH}$ gradient is indicated in the colour bar at the right-hand side. PDB files used in this illustration: $3 \cup X 4$ [15] (Urel; blue), 4XFW [16] (aCA; orange) and 1E9Y [17] (Urease; grey). The red structure shown twice in the outer membrane, is a homology model (H. pylori OMPLA model based on the 1QD5 [14] PDB template). The purple and turquoise proteins embedded in the right-front corner of the IM are COG0733 transporter models. We suggest these transporters can diffuse $\mathrm{NH}_{4}^{+}$(and $\mathrm{NH}_{3}$ ?) across the IM (we call them ammonium channels I and II, AmCl and AmCll; these models are based on the 4US3 [18] PDB template structure). This figure does not reflect real-life concentrations

\section{Results}

Our bioinformatics work, combined with an extensive literature study, and backed up by experimental work on 
variants with non-functional OMPLA is summarized in Fig. 1. The remainder of this article discusses all aspects of this model.

\section{Survival of $H$. pylori OMPLA variants in acidic environment} Sequencing the variants revealed classical phase variants displaying shorter OMPLA sequences in euBL, euAP, and euBF; see Table 1 . Two variants (euBZ and euBB; see Table 1) have missense mutations resulting in a non-functional OMPLA. Under prolonged growth in acidic $\mathrm{pH}$ conditions, only those with an ON phase and/or without missense mutations survive [12]. Thus, OMPLA $A_{\text {OFF }}$ is non-functional OMPLA due to either a truncated OMPLA or a missense mutation. All five OFF variants grow at neutral $\mathrm{pH}$, lacking OMPLA activity and they do not survive at all at low $\mathrm{pH}$.

The existence of these variants further emphasizes the importance of OMPLA for survival at low $\mathrm{pH}$.

\section{H. pylori OMPLA 3D structure model}

A total of 3084 sequences were included in the OMPLA Multiple Sequence Alignment (MSA; see Additional file 2). Extracting E. coli and H. pylori OMPLA sequences from the MSA yielded the sequence alignment shown in Fig. 2a. This alignment was used to construct the OMPLA 3D structure model. The extracted $H$. pylori OMPLA sequence is compared to the original unaligned sequence (HPeuAN, GenBank Accession ID: AFR51731) in Fig. 2b. H. pylori OMPLA has a 38-residues long insert (the so-called 'not-modelled insert' that is highlighted yellow in Fig. 2b). This region consists of a sequence not found in the template E. coli sequence, and Blastp only finds acid-tolerant gastric Helicobacteraceae containing this sequence element.
The YASARA/WHAT IF twinset predicts that this insert constitutes a loop without any regular secondary structure.

The MSA was used for entropy-variability analyses (EVA), and Fig. 3 shows the resulting EV plot for OMPLA sequences, which were mapped onto the $H$. pylori OMPLA model structure in Fig. 4. There are highly variable (blue) residues located in the exterior loops, while the most conserved (red) residues are located in the trimer interface, the active site, and the calcium-binding site, while a few are located in extracellular loops. The highly conserved extracellular loop-residues, that must have an important function for OMPLA, include two tyrosine residues: Y233 and Y240 in loops 4 and 6, respectively (see Fig. 4a, b).

The resulting 3D structure model of $H$. pylori OMPLA shows that molecules like urea and ammonium could easily pass through the $H$. pylori OMPLA pore which has a diameter of at least $4 \AA$, which is much wider than the $1.5 \AA$ diameter of the UreI (see Fig. 5; see Additional file 3 ) pore that is known to let urea pass into the cytosol (see Additional file 1).

The differences in pore size and amino acid composition between the $H$. pylori OMPLA model and $E$. coli OMPLA structure are visualized in Fig. 6.

\section{Sequence similarities in acid tolerant species of the Helicobacteraceae family}

The not-modelled sequence highlighted in Fig. $2 \mathrm{~b}$ is found in nearly all gastric Helicobacter species, but is lacking in enterohepatic Helicobacter species (see Table 2; Fig. 7). H. pylori's OMPLA shares the highest sequence identity with other gastric Helicobacter OMPLAs, and we will explore how they differ from enterohepatic Helicobacters (see Fig. 7).

Table 1 Characteristic of $\boldsymbol{H}$. pylori colony variants showing altered phospholipase $A$ activity

\begin{tabular}{|c|c|c|c|c|c|}
\hline \multicolumn{2}{|c|}{ H. pylori isolates } & \multirow{2}{*}{$\begin{array}{l}\text { OMPLA length (amino } \\
\text { acids) } \\
355\end{array}$} & \multirow{2}{*}{$\begin{array}{l}\text { Enzyme activity } \\
\text { Yes }\end{array}$} & \multirow{2}{*}{$\begin{array}{l}\text { Truncated OMPLA or missense } \\
\text { mutation? } \\
-\end{array}$} & \multirow{2}{*}{$\begin{array}{l}\begin{array}{l}\text { Sequence ID } \\
\text { (GenBank ID) }\end{array} \\
\text { AFR51755.1 }\end{array}$} \\
\hline euBL (98019) & OMPLA ${ }_{\mathrm{ON}}$ & & & & \\
\hline & OMPLA ${ }_{\text {OFF }}$ & 263 & No & Truncated OMPLA & $\mathrm{N} / \mathrm{A}$ \\
\hline \multirow[t]{2}{*}{$\operatorname{euAP}(29 A)$} & OMPLA $A_{O N}$ & 355 & Yes & - & AFR51733.1 \\
\hline & OMPLA $A_{\text {OFF }}$ & 265 & No & Truncated OMPLA & $\mathrm{N} / \mathrm{A}$ \\
\hline \multirow[t]{2}{*}{$\operatorname{euBF}(5 A)$} & OMPLA ${ }_{O N}$ & 355 & Yes & - & AFR51749.1 \\
\hline & OMPLA $A_{\text {OFF }}$ & 263 & No & Truncated OMPLA & $\mathrm{N} / \mathrm{A}$ \\
\hline \multirow[t]{2}{*}{ euBZ (9B) } & OMPLA ${ }_{O N}$ & 355 & Yes & - & AFR51769.1 \\
\hline & OMPLA $_{\text {OFF }}$ & 355 & No & Missense mutation (Pro157Ser) & $\mathrm{N} / \mathrm{A}$ \\
\hline \multirow[t]{2}{*}{ euBB (53A) } & OMPLA ${ }_{O N}$ & 355 & Yes & - & AFR51745.1 \\
\hline & OMPLA ${ }_{\text {OFF }}$ & 355 & No & Missense mutation (Ser235Arg) & N/A \\
\hline
\end{tabular}

The isolates used in this article are the same as previously published [14] 


\section{Sequence Alignments}

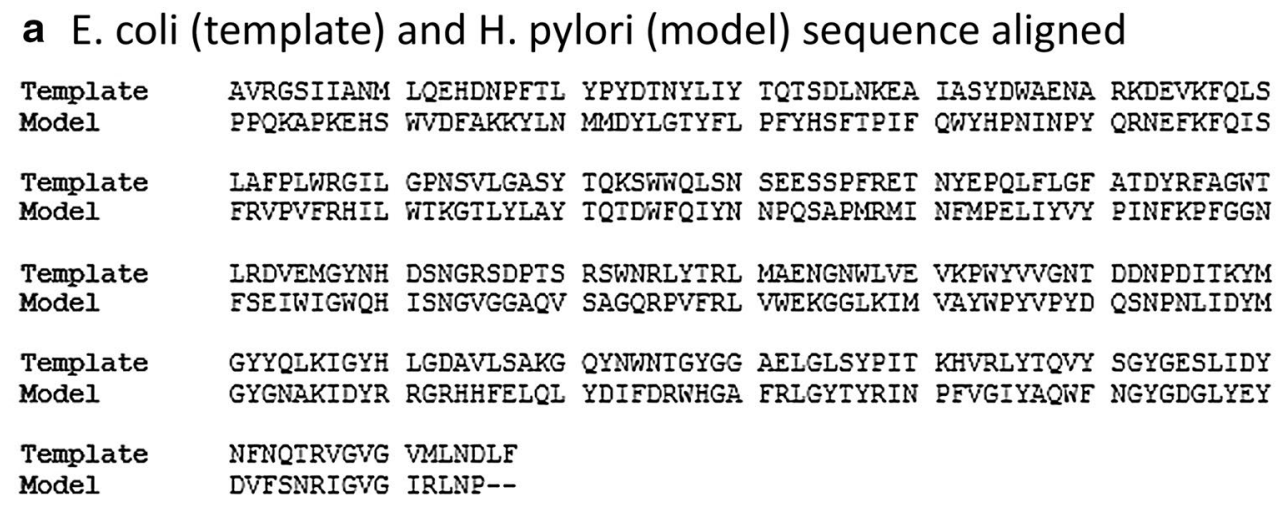

\section{b H. pylori original and model sequence aligned}

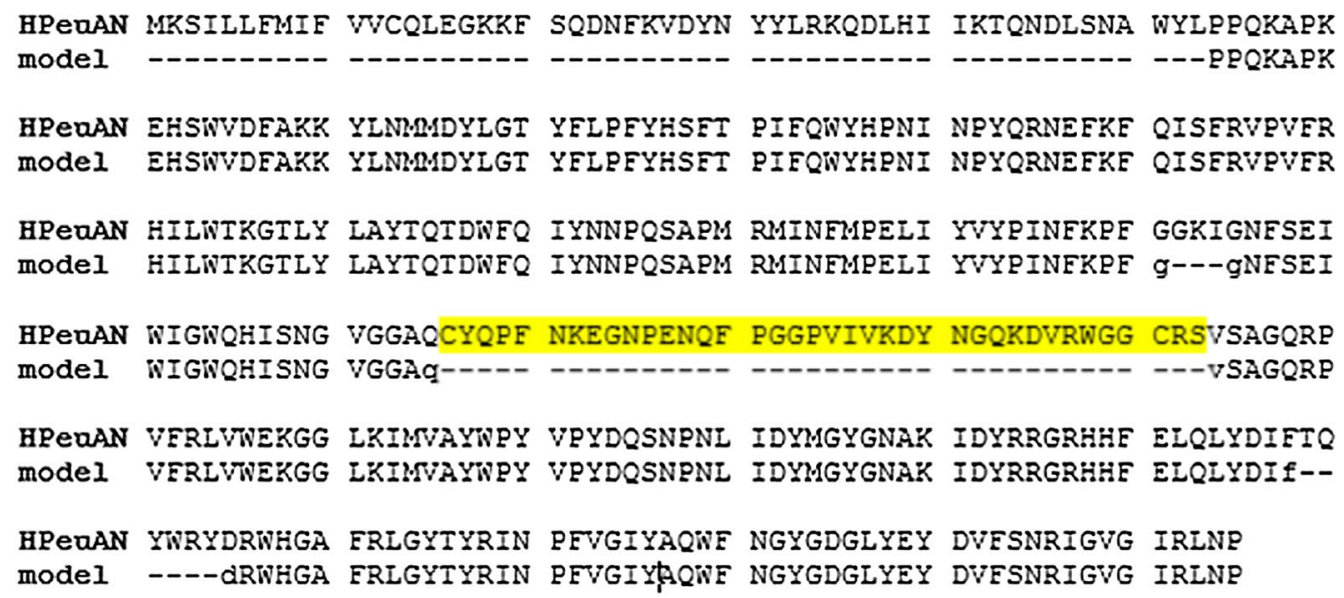

Fig. 2 Sequence alignments. The sequence alignment used in constructing a homology model of H. pylori OMPLA from E. coli OMPLA (1QD5 PDB template file). a The model (H. pylori OMPLA) and template (E. coli OMPLA) sequences extracted from the MSA (see Additional file 2). b The original HPeuAN sequence (GenBank Accession ID: AFR51731) aligned to the model sequence extracted from the MSA. The highlighted yellow fragment is the not-modelled 38 residues long insert

\section{In silico pldA operon prediction}

Figure 8 shows how the OMPLA gene, pldA, is organized in gastric Helicobacters compared to a series of other bacteria. Gastric Helicobacter species have a common operon organization in which pldA lies downstream of two channels that belong to the COG0733 family that is also known as ' $\mathrm{Na}^{+}$-dependent transporters (channels) of the SNF family' (AmCI and AmCII). According to ProOpDB pldA is not part of any operon in enterohepatic $H$. hepaticus (see Fig. 8 b). In Table 3 we explore the differences between the gastric and enterohepatic Helicobacter gene organizations. It is clearly seen that the AmCI and AmCII channel are found only in the pldA operon of gastric Helicobacter species, which strongly suggests a role in $\mathrm{pH}$ management.

\section{D modelling of IM channels}

The model depicted in Fig. 1 includes two channels to allow $\mathrm{NH}_{3} / \mathrm{NH}_{4}{ }^{+}$to pass from the cytosol to the periplasm. We constructed 3D models for AmCI and AmCII as described for OMPLA, with the same methodology that was used for the analyses of porins [16]. AmCI and AmCII share a pairwise sequence identity of $31-34 \%$ to the template, and $\sim 50 \%$ to each other. The results are shown in Fig. 9. Visual inspection of these models reveals that $\mathrm{AmCI}$ has a more polar pore and thus might be the 


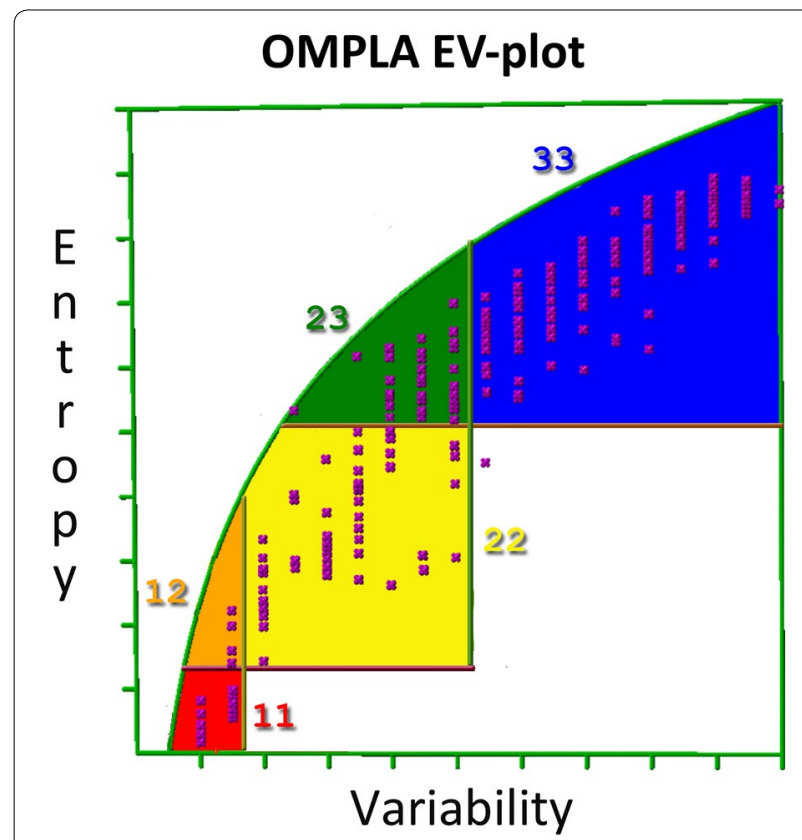

Fig. 3 EV-plot for 3084 OMPLA sequences. Each box represents a class of entropy-variability and is coloured as described in the "Methods" section

channel for $\mathrm{NH}_{4}{ }^{+}$, while AmCII pore is more hydrophobic and thus seems more suitable for letting $\mathrm{NH}_{3}$ diffuse to the periplasm. It is also not yet clear if the activity of either of these two channels is a function of either the cytosolic or the periplasmic $\mathrm{pH}$, and we do not (yet) know if AmCI and/or AmCII are sodium symporter or antiporters, or perhaps they even are simple channels and not transporters. Most well characterized sodium or sodium and chlorine dependent transporters have much longer sequences than $\mathrm{AmCI}$ and $\mathrm{AmCII}$, suggesting that AmCI and AmCII might miss the co-transporter related domains. Further experiments are needed to answer all these questions, but both the operon structure and the 3D models do not disagree with the idea that AmCI and AmCII help ammonia/ammonium travel from the cytosol to the periplasm.

\section{Discussion}

The H. pylori acid regulation pathway has been well studied and often debated (see Additional file 1 for further details) [1], but all currently available functional models still require unknown OM components for urea influx and ammonium efflux. Our in silico results indicate that H. pylori OMPLA can be an OM urea and ammonium channel, while AmCI and AmCII, that are likely co-regulated with OMPLA, can be involved in ammonium efflux from the cytosol. The hypothesis presented in this paper, depicted in Fig. 1, is mainly based on in silico models combined with current literature findings on the urea pathway and $H$. pylori acid tolerance.

Unlike E. coli OMPLA, H. pylori OMPLA is continuously breaking down membrane phospholipids to lysophospholipids when cultivated at physiological $\mathrm{pH}$ [17]. The optimal $\mathrm{pH}$ for OMPLA's enzymatic activity is around 7.0, and this activity is abolished at pH 5.0 or lower, yet this protein is required for in vitro survival at very low $\mathrm{pH}[12]$.

The OMPLA structure is composed of a 12-stranded transmembrane $\beta$-barrel with short periplasmic turns and long extracellular loops. This is consistent with the structure of other outer membrane proteins (OMPs; including that of porins, the largest OMP subfamily) that diffuse molecules through the membrane [16]. The $H$. pylori OMPLA barrel is large enough to have pore activity [16]. Figure 5 supports the idea that there is enough space for urea to pass the OM through OMPLA. The pores of the $E$. coli and $H$. pylori OMPLA vary in shape and amino acid composition, as shown in Fig. 6, supporting our hypothesis that they differ in function. We therefore suggest that $H$. pylori OMPLA is a multifunctional protein with one function being a phospholipase and a second function being acid protection.

Standard sequence alignment methods are reliable for closely related sequences, but often fail when diverse sequences-like OMPLAs- are analysed [18, 19]. The alignment of the $H$. pylori OMPLA sequence with the sequence of the E. coli OMPLA template structure (1QD5 PDB) is complicated. To get this alignment we collected as much information as possible about homologous OMPLA sequences and generated a MSA using an iterative profile alignment process. Unlike standard sequence alignment methods, iterative profile alignments can use both structure and function information. The $H$. pylori and E. coli OMPLA protein sequences are highly different (see Additional file 2) and their sequence identity is just above the threshold for homology modelling [20] when the not-modelled insert (Fig. 2) is not taken into account.

EV analyses the evolutionary footprint left behind in a MSA and identifies regions in the protein in which conservation and variation relate to various aspects of thee protein's function $[16,19]$. The highly variable residues (coloured blue in Fig. 4) observed mainly at the outside facing loops likely are (a-specifically) involved in host evasion [16]. The two highly conserved loop tyrosines (Fig. 4) are located far from the trimer interface, yet they must be functionally important because they are conserved in the MSA.

Most gastric Helicobacters have a sequence insert that is lacking in the enterohepatic Helicobacters (and other species). Table 2 shows two gastric Helicobacters that 


\section{H. pylori OMPLA model}
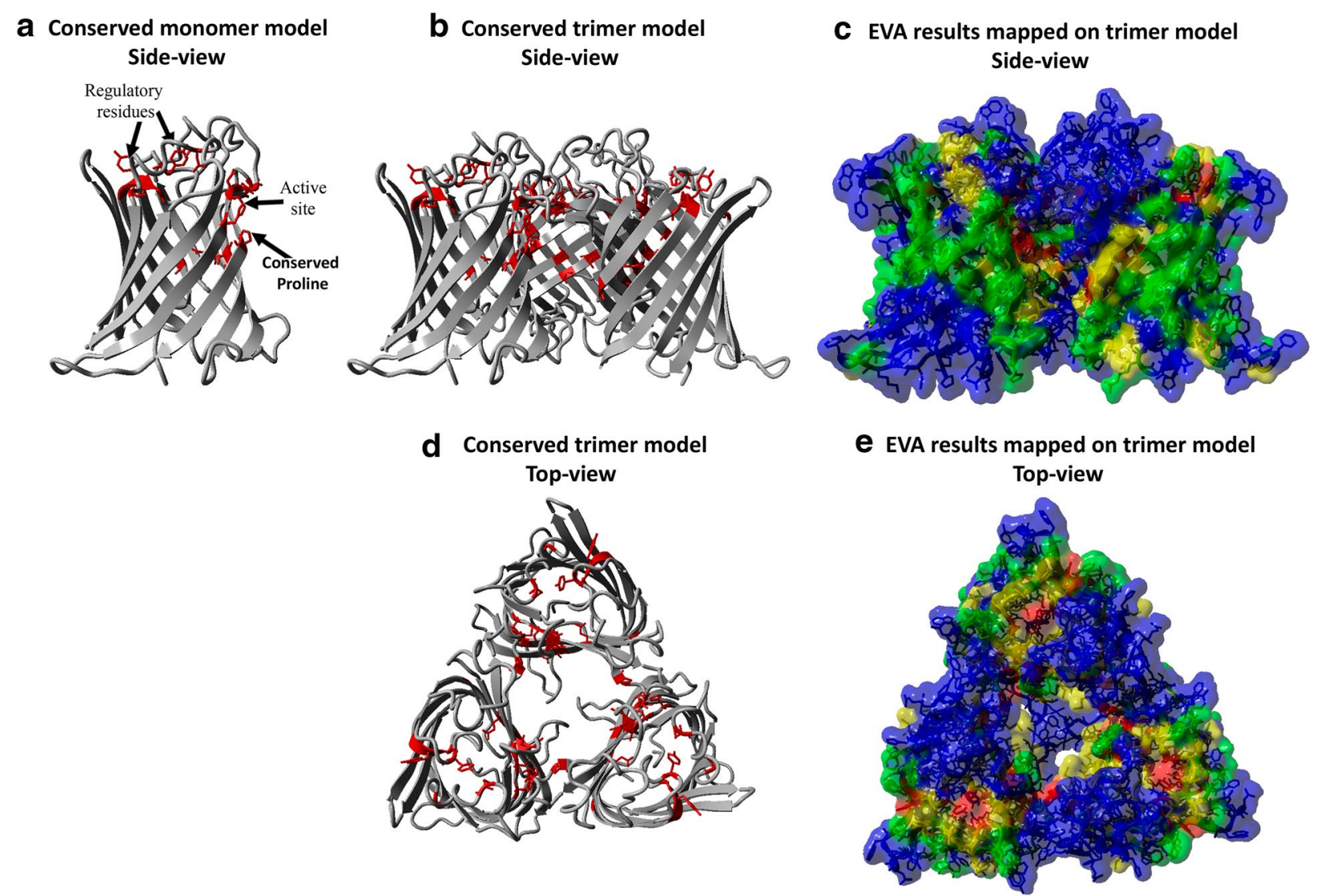

Fig. 4 EVA and H. pylori OMPLA model. a The most conserved residues are shown as red stick model on a OMPLA monomer model (side view) in which the active site is indicated. $\mathbf{b}$ As a, but now a OMPLA trimer is used. $\mathbf{c}$ EVA results mapped on the H. pylori OMPLA all-atom trimer (side view) coloured by EV-plot section. $\mathbf{d}$ As $\mathbf{b}$, but top view. e As c, but top view. The blue residues that cover the trimeric hole are periplasmic loop residues (coloured grey in d)

are very different and that lack this sequence insert: Helicobacter mustelae and Helicobacter himalayensis. In phylogenetic analyses, $H$. mustelae cluster with enterohepatic Helicobacters [21]. The genome from H. mustelae type strain 12,198 [22] lacks pldA, the gene coding for OMPLA. H. mustelae possess a nickel-independent urease, called UreAB2 [23]. In the presence of urea this metalloprotein is by itself already sufficient for the bacteria to survive acid shock. It is activated by ferrous ions in the absence of auxiliary proteins [23]. H. mustelae has adapted a different mechanism to survive in the stomach of its host, the ferret. The other gastric species that differs, $H$. himalayensis lacks urease genes, which indicates that it lacks the whole urease pathway. Generally, gastric and enterohepatic Helicobacter OMPLAs are quite different; enterohepatic Helicobacters lack the insert found in most gastric Helicobacters, except the OMPLAs from $H$. mustelae and $H$. himalayensis, that seem to have evolved totally different systems to cope with low $\mathrm{pH}$.

The not-modelled insert is similar to that found in the sequence alignment of a subset of sequences presented by Istvan et al. [11]. This not-modelled insert (see Table 2; Figs. 2, 7 for more details) can be of importance for $\mathrm{pH}$ gating as observed in other proteins such as $H$. pylori UreI [24] and E. coli OmpG [25]. pH sensitivity has also been detected in the E. coli OmpF constriction loop [26].

We do not know the function of the residues in the predicted extracellular loop (the not-modelled insert highlighted in Fig. 2b), but literature has shown that mutating a charged extracellular loop residue can have deleterious effects on acid survival $[27,28]$. Our laboratory results (the missense mutations P157S and S235R, see Additional 


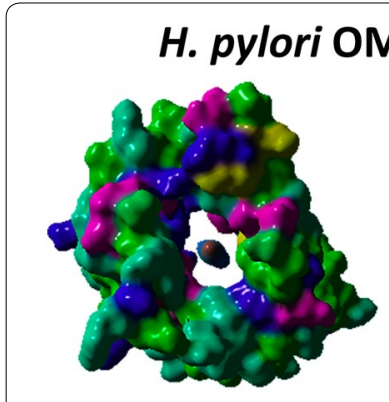

a

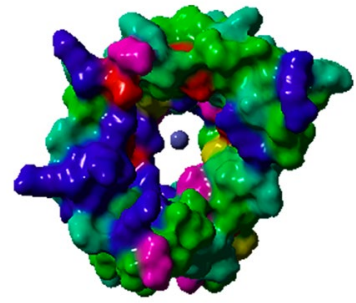

b
Fig. 5 OMPLA pore. Both OMPLA and substrates are visualized with their molecular surface using YASARA/WHAT IF twinset. Urea and $\mathrm{NH}_{4}{ }^{+}$(and perhaps $\mathrm{NH}_{3}$ ) easily pass through the OMPLA polar pore. Positively charged residues (Arg, Lys, and His) are coloured blue, negatively charged residues (Glue, and Asp) are coloured red, polar residues (Asn, and GIn) are coloured purple, hydrophobic residues (Gly, Ala, Val, Leu, and Pro) are coloured grass green, alcoholic residues (Thr and Ser) are coloured light green, aromatic residues (Phe, Tyr, and Trp) are coloured light blue-green, and sulphur containing residues (Cys, Met). a Top-view w/urea. b Bottom-view w/ammonium

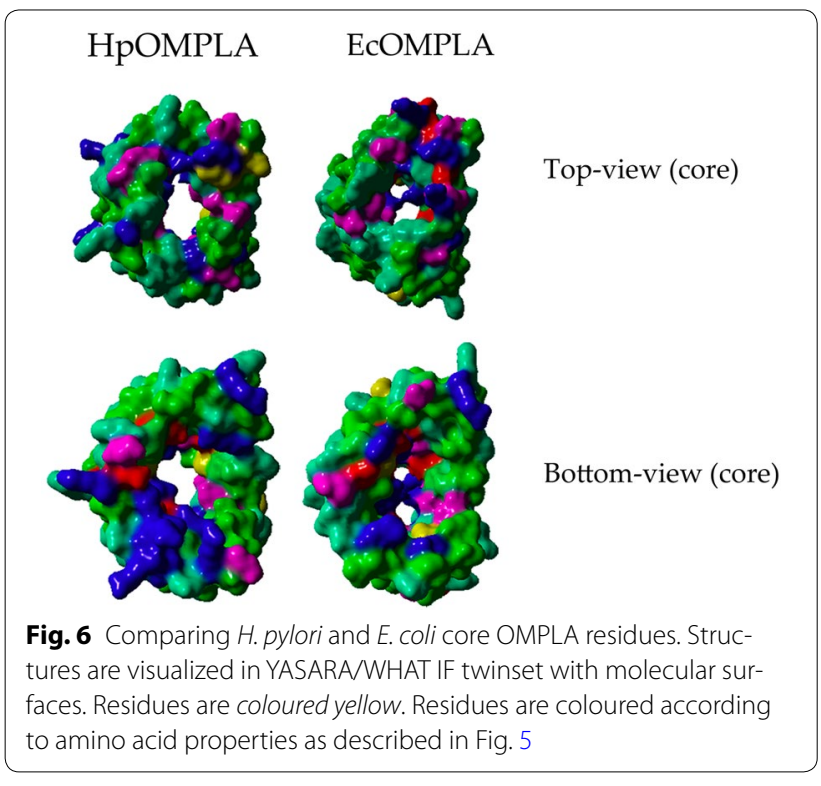

file 5 for residue numbering) revealed the importance of these two OMPLA residues. Ser235 is located in the notmodelled loop insert. Arginine is a positively charged residue and its introduction will lead to electrostatic changes, perhaps resulting in a functionally closed pore. P157 is one of the highly-conserved residues. It is located at the trimer interface (see Fig. 4). This mutation likely destabilizes the $\beta$-barrel structure $[16,29,30]$, or might disable acidic protection by disturbing the trimer interface that is required for pore-activity [16]. The conserved cysteines, found in the gastric Helicobacter OMPLA lie in this extracellular loop. Cys residues are seldom found in OMPs [31] and they are seldom found facing the surface; however, conserved cysteines have a wide range of functions and are usually of great importance to the protein [32-34]. Although protein stabilization would be a likely function for this conserved disulfide bond, further laboratory work is needed to confirm its function. Inspection of the model suggests that Y240 stabilizes the extracellular loops; especially the interactions between the first and third extracellular loop. We have previously predicted that all porins function as a trimer [16], and provided evidence that OMPLA forms a trimeric structure too. The Y233 is located near the putative trimeric hole. This suggests a regulatory role for this residue, but what that role might be remains unclear.

OMPLA's operon structure sheds light on other relevant proteins in the urea pathway (see Fig. 1). The gastric and enterohepatic Helicobacter species have different operon organizations, as illustrated in Fig. 8. Genes located in the same operon normally show co-expression and tend to be regulated by the same promoter. Price et al. found that the life-cycle of an operon is under strong selection [35] and genes found in the same operon are likely involved in the same process [36, 37]. Gastric Helicobacters have a different gene expression compared to enterohepatic Helicobacters, including a higher level of urease expression [23]. The hosts of the gastric Helicobacter group are more diverse than the hosts of the enterohepatic group, but their pldA operons nevertheless are more similar to each other; some consisting of five consecutive genes (2 SLC6sbd_Tyt1-Like genes, pldA, dnaN, and $g y r B$ ). The two transporter (channel) genes upstream of the pldA gene are generally predicted to lie in the same operon as pldA in gastric Helicobacters, as shown in Table 3. The gene encoding AmCI is also predicted to be phase variable (see Table 3). The two gastric bacteria $H$. himalayensis (lacking the urease genes) and H. mustelae (lacking the pldA gene) and enterohepatic Helicobacters, have different organization and they have probably evolved different mechanisms for acid adaptation.

Homology searches in clusters of orthologous groups (COGs) database [37] revealed that AmCI and AmCII both belong to COG0733 $\left(\mathrm{Na}^{+}\right.$-dependent transporters (channels) of the SNF family). Since genes in an operon are regulated together, the two $\mathrm{Na}^{+}$-dependent transporters (channels) of the SNF family (AmCI and AmCII) are also likely implicated in acid survival and we suggest that they are involved in ammonium/ ammonia transport or diffusion from the cytosol to the periplasm. We do not know why two very similar channels are needed in this process, but visual inspection of their 3D structure models suggests the possibility 
Table 2 Non-modelled OMPLA insert in Helicobacter sequences

\begin{tabular}{llll}
\hline Species & Representative strain & Classification & Predicted loop insert \\
\hline H. acinonychis & Sheeba & Gastric & Insert \\
H. bizzozeronii & CIII-1 & Gastric & Insert \\
H. cetorum & MIT 99-5656 & Gastric & Insert \\
H. heilmannii & ASB1.4 & Gastric & Insert \\
H. pylori & ATCC 43504 & Gastric & Insert \\
H. suis & HS5 (partially sequenced) & Insert \\
H. felis & ATCC 49179 & Gastric & Insert \\
H. mustelae & 12198 & Gastric & NA \\
H. himalayensis & YS1 & Gastric & No insert \\
H. bilis & ATCC 43879 & Gastric & Short insert \\
H. canadensis & MIT 98-5491 & Enterohepatic & No insert \\
H. canis & NCTC 12740 & Enterohepatic & No insert \\
H. cinaedi & CCUG 18818 = ATCC BAA-847 & Enterohepatic & No insert \\
H. fennelliae & MRY 12-0050 & Enterohepatic & Short insert \\
H. hepaticus & ATCC 51449 & Enterohepatic & No insert \\
H. muridarum & ST-1 & Enterohepatic & Short insert \\
H. pullorum & MIT 98-5489 & Enterohepatic & No insert \\
H. rodentium & ATCC 700285 & Enterohepatic & No insert \\
H. trogontum & ATCC 700114 & Enterohepatic & No insert \\
H. typhlonicus & MIT 97-6810 & Enterohepatic & No insert \\
H. winghamensis & ATCC BAA-430 & Enterohepatic & No insert \\
Thistablelists Helicobater & Enterohepatic & \\
\end{tabular}

This table lists Helicobacter species, strain, classification (gastric vs enterohepatic) and whether the OMPLA sequences contain the predicted loop. The "Predicted loop insert" - column lists those species that have a long, unique insert that could not be modelled, but predicted to be a longer loop. They are typically found in gastric bacteria. The term "short insert" indicates shorter loops, likely to have a different function based on their residue composition. See Additional file 4 for the sequence alignment file

\section{Non-modelled Helicobacter OMPLA insert sequence}

H. cetorum EVWIGWQHISNGVGGAECYQPFNRQGNPENQFPSQPVVVRNYNGQRNVR----WGGCRSVSAGQR: H. acinonychis EIWAGWQHISNGVGGAECYQPFNKEGNPENQFPGQPVVVRDYNGQRNVR----WGGCRSVSAGQR: H. pylori EIWIGWQHISNGVGGAQCYQP FNREGNPENQFPGQPVIVKDYNGQRDVR----WGGCRSVSAGQR H. bizzozeronii EFWIGWQHISNGIGGRQCYQPFR-NGNPTDAFPGTPVHITEENRQIIVQQGGLDGGCRSVSAGQR: H. felis EEWIGWQHISNGIGGRQCYQPER-NGNPTDAFPGTPIHITEENKNIIVQQGGIDGGCRSVSAGQR H. heilmannii EFWIGWQHISNGIGGRQCFQPYR-NGNAIGPFPGTPVHITEEDRQVIIQAGGLDGGCRSVSAGQR: H. suis EFWIGWQHISNGIGGRQCYQPYA-NGNAIGAFPGNPVTVIREDGQRV-----YEGGCRSVSAGQR H. fennelliae ELRIGFLHYSNGIGGDECVRDANNN--S-------------------------SPNCRSRSGANR H. bilis ELRIGYLHFSNGIGGDECIRDSNRN--PI-----------------------TPERCRSRSMGNR H. muridarum ELRIGLTHYSNGIGGEECIRNDLDD--P------------------------TPRDCRSRSAGNR

H. winghamensis RVNEGYVHQSNGGDII----- - - -

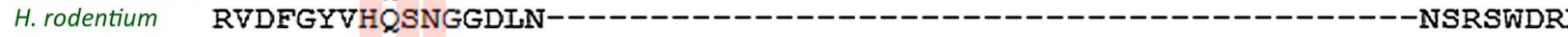
H. canadensis RVNFGYLHOSNGGDIE-- - - - - - - - - - - - - - - - - - - - - - - - - - - - HSRSWDR

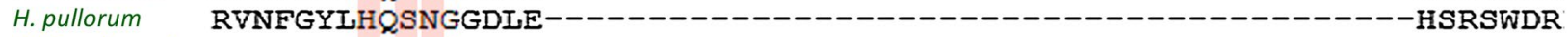

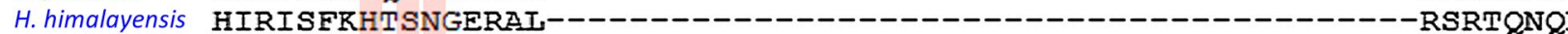

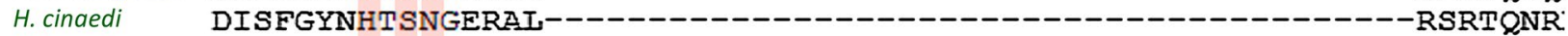

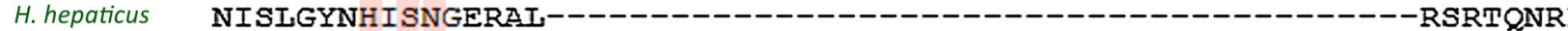
H. typhlonius DISFGYNHISNGERAI----------------------------------------RSRTQNR H. canis TMRIGYIHLSNGERRDNLVVGE--------------ADIRNEGIS-----KDDPGWLRRSKSIDR H. trogontum WFSIGYNHVSNGERENVNSADP-----------------R----Q-----AEWGGNEVRSRAIDR'

Fig. 7 Not-modelled insert sequence. The alignment of the inserted region among the Helicobacter species is shown (see Table 2 for more information). The residues highlighted in red constitute the catalytic triad in OMPLA. Gastric species names are in blue; enterohepatic species names are in green. The $H$. himalayensis YS1 genome lacks urease genes, indicating lack of the urease pathway 


\section{pldA operon}

\section{a Subset of proteobacteria pldA operons}

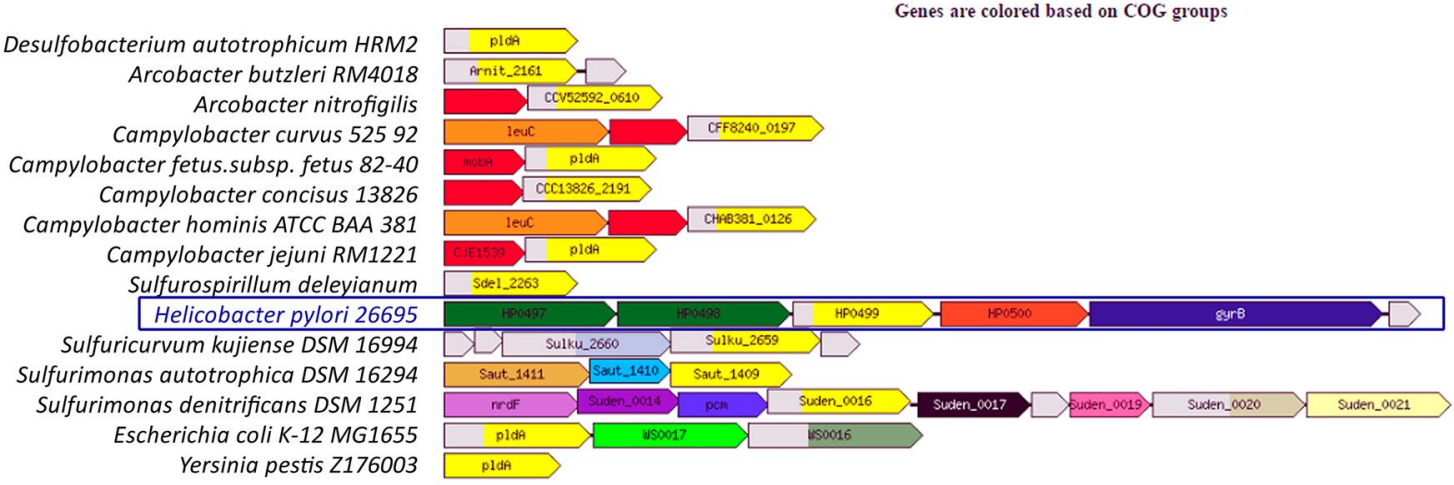

b Helicobacter pldA operon

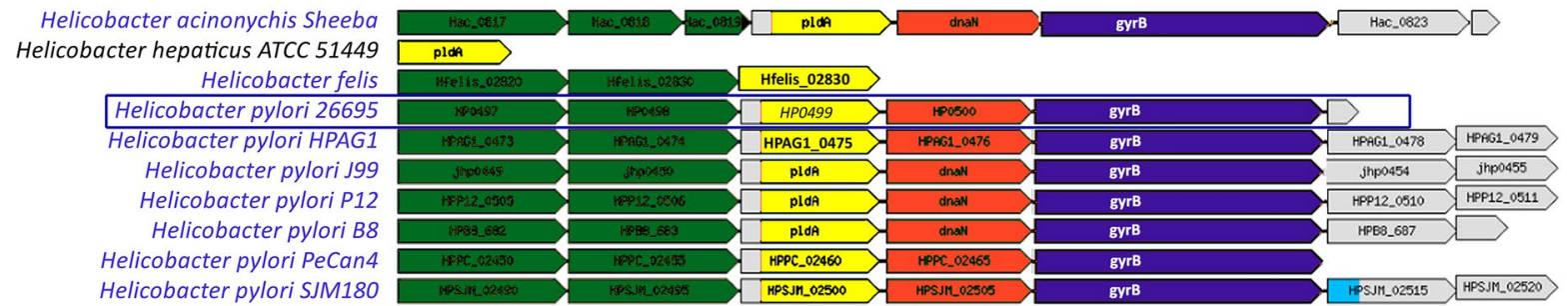

Fig. 8 pldA operon prediction. Operon prediction for clusters of orthologous groups (COGs) COG2829 (OMPLA; or pldA on gene-level) using ProOpDB where a illustrates a subset of proteobacteria, including H. pylori, E. coli and Yersinia pestis and $\mathbf{b}$ illustrates the Helicobacters found in the ProOpDB. Gastric Helicobacter bacteria are highlighted in blue. Each colour represents a COG, except grey which indicate genes with an unknown COG. Yellow represents pldA (COG2829); $\mathrm{Na}^{+}$-dependent AmCl and AmCll (COG0377) coloured green; dnaN (COG0592) coloured orange and gyrB (COG0187) coloured purple

that one of the channels can be ammonium specific while the other is specific for ammonia. While the OMPLA family (COG2829) is mainly found in Proteobacteria, $\mathrm{Na}^{+}$-dependent COG0733 channels are widespread throughout bacteria and eukaryotes. In order to better understand the possible role of these proteins in the urea pathway (being co-regulated with OMPLA), 3D model structures were constructed for AmCI and AmCII (see Fig. 9). The AmCI and AmCII transporters have closest sequence similarity with Bacillus halodurans MhsT (a BLAST search against the PDB resulted in $31-35 \%$ sequence identity for the H. pylori HP0497 and HP0498 sequences). MhsT is a $\mathrm{Na}^{+}$-dependent neurotransmitter/sodium symporter and belong to the SLC6 family of $\mathrm{Na}^{+} / \mathrm{Cl}^{-}$-dependent neurotransmitter transporters. These proteins transport small substances, e.g. amino acids or similar structures [38, 39]. The substrates found among SLC6 transporters include glycine, serotonin, dopamine, and norepinephrine [40]. They have a so-called $5+5$ core helix motif that is embedded in the membrane, albeit that we cannot exclude the presence of more helices; MhsT, for example, has 11 helices, while LeuT has 12 helices [38]. Evolutionary, these transporters adjust quickly to changes; some of them, for example, are voltage-gated channels under certain conditions [41]. We believe that the two putative ammonium channels, AmCI and AmCII, are located in the inner membrane, because helical proteins are seldom found in the outer membrane of Gram-negative bacteria [16]. Likely functions include $\mathrm{pH}$ sensing, or solute transport of small substances that are involved in buffering the environment [42-46]. We hypothesize that since they are coregulated with OMPLA, these transporters are involved in the urea pathway, as shown in Fig. 1. Since there are currently no $\mathrm{NH}_{4}{ }^{+}$channels known, we believe the two COG0733 are better candidates than the suggested UreI. UreI have an important role in urea influx, but no experiments show a role for UreI in ammonium efflux [42]. 
Table 3 Operon prediction

\begin{tabular}{|c|c|c|c|c|c|}
\hline Species & Representative strain & Host & Classification & Upstream & Downstream \\
\hline H. acinonychis & Sheeba & Cheetah & Gastric & $\mathrm{AmCl}$ and $\mathrm{AmCll}$ & dnaN, gyrB, 2 hypothetical genes \\
\hline H. cetorum & MIT 99-5656 & Dolphin & Gastric & $\mathrm{AmCl}^{*}$ and $\mathrm{AmCll}$ & dnaN, gyrB \\
\hline H. pylori & ATCC 43504 & Human & Gastric & $\mathrm{AmCl}$ and $\mathrm{AmCll}$ & dnaN, gyrB, 2 hypothetical genes \\
\hline H. bizzozeronii & ClII-1 & Human & Gastric & $\mathrm{AmCl}$ and $\mathrm{AmCll}$ & No \\
\hline H. himalayensis & YS1 & Marmota himalayana & Gastric & No & No \\
\hline H. suis & HS5 & Swine & Gastric & $\mathrm{AmCl}$ and $\mathrm{AmCll}$ & No \\
\hline H. felis & ATCC 49179 & Cat & Gastric & $\mathrm{AmCl}$ and $\mathrm{AmCll}$ & No \\
\hline H. mustelae & 12198 & Ferret & Gastric & No & No \\
\hline H. heilmannii & ASB1.4 & Cat & Gastric & $\mathrm{AmCl}^{*}$ and $\mathrm{AmCll}$ & No \\
\hline H. bilis & ATCC 43879 & Human & Enterohepatic & No & No \\
\hline H. canadensis & MIT 98-5491 & Human & Enterohepatic & No & No \\
\hline H. canis & NCTC 12740 & Human & Enterohepatic & No & pseH \\
\hline H. cinaedi & CCUG $18818=$ ATCC BAA-847 & Human & Enterohepatic & No & metE \\
\hline H. fennelliae & MRY 12-0050 & Human & Enterohepatic & Hypothetical & SAM-dependent MTase genes \\
\hline H. hepaticus & ATCC 51449 & Mouse & Enterohepatic & No & met $E$, and gene encoding NADPH \\
\hline H. muridarum & ST-1 & Rat & Enterohepatic & No & $\mathrm{ABC}$ transporter gene \\
\hline H.pullorum & MIT 98-5489 & Human & Enterohepatic & No & No \\
\hline H. rodentium & ATCC 700285 & Mouse & Enterohepatic & No & No \\
\hline H. trogontum & ATCC 700114 & Rat & Enterohepatic & No & No \\
\hline H. typhlonicus & MIT 97-6810 & Mouse & Enterohepatic & No & No \\
\hline H. winghamensis & ATCC BAA-430 & Human & Enterohepatic & No & No \\
\hline
\end{tabular}

Operon prediction comparing gastric and enterohepatic genes upstream/downstream from pldA. Helicobacter species. Operons are predicted by Fgenesb software (Softberry Inc., Mount Kisco, NY, US). COG0377 corresponds to the "Na+-dependent transporters (channels) of the SNF family" (this includes AmCl and AmClI). The COG0377 are phase variable genes

* Truncated proteins

\section{Conclusions}

OMPs have multiple functions that aid adaptation in rapidly changing environments [16]. Current literature does not explain which $H$. pylori OMP is involved in maintaining higher periplasmic $\mathrm{pH}$ level compared to the acidic

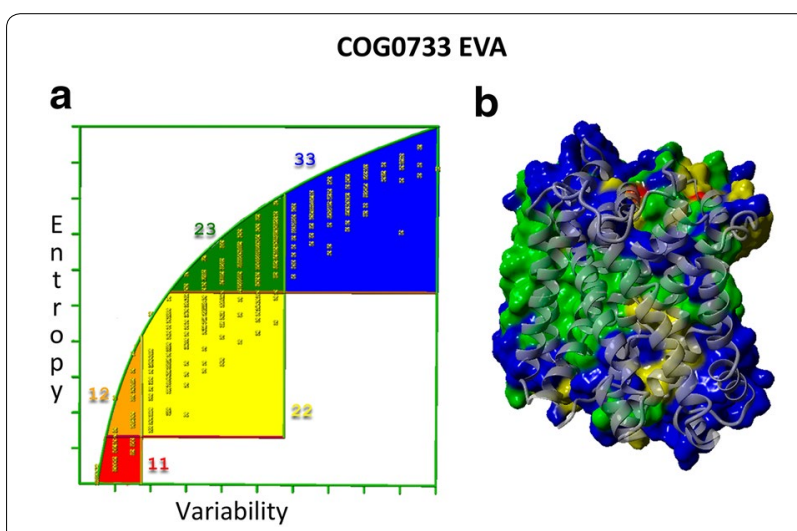

Fig. 9 EVA for 4444 COG0733 sequences. EV-plot to the left with the residues mapped onto the MhsT structure to the right (4US3 PDB template file). Each box represents a degree of entropy-variability and is coloured as described in "Methods" section. a EV-plot. b EVA mapped onto MhsT outside environment. In silico protein structure modelling of $H$. pylori OMPLA indicates a transmembrane pore of $4 \AA$, and $H$. pylori OMPLA could participate in acid protection through this transmembrane pore. Our group has previously linked intact $H$. pylori OMPLA to an increased risk for ulcer disease [47]. A possible explanation for this could be its role in the urea pathway that concludes with the efflux of ammonium that is implicated in ulcer formation.

We propose that urea passes through OMPLA into the periplasm, while ammonium might exit to increase the cytoplasmic and periplasmic $\mathrm{pH}$. Since acid tolerance is observed only when OMPLA is intact, we suggest that OMPLA's role is to maintain an optimal periplasmic $\mathrm{pH}$ as modelled in Fig. 9. We hypothesize that AmCI and AmCII, which are co-regulated with OMPLA, are also implicated in acid protection allowing $\mathrm{NH}_{3} / \mathrm{NH}_{4}{ }^{+}$to move from the cytoplasm to the periplasm. We propose that OMPLA also is involved in the secretion of $\mathrm{NH}_{4}^{+}$ from the cell. That gives OMPLA two transport roles -urea influx and, ammonium efflux- which is possible because it is likely constitutively expressed (as observed in other pathogenic bacteria [33]) which suggests that it probably is abundantly present in the outer membrane. 


\section{Methods}

Survival of $\boldsymbol{H}$. pylori OMPLA variants in acidic environment We collected $H$. pylori clinical isolates in four hospitals in the Oslo region, Norway [12, 14]. 57 isolates were examined for spontaneous colony variants showing altered phospholipase A activity by thin-layer chromatography (TLC) as previously described [47]. Isogenicity of five selected variant pairs were confirmed by amplified fragment length polymorphism (AFLP) as previously described [12]. From each variant, the pldA gene was sequenced as previously described [47], in order to detect the genetic background for the OMPLA phenotype (Table 1). Survival of the selected variants at $\mathrm{pH} 3.5$ was determined as previously described [12]. See Additional file 1 for more information.

\section{Operon predictions}

ProOpDB [36] predicts operon structures of prokaryotic genomes, and presents results in figures in which all genes in a clusters of ortholog genes (COG) have the same colour. We used this software to determine all genes in the same operon as OMPLA. Not all species are represented in this database, so the genes used to analyse gastric vs enterohepatic Helicobacters were analysed in Fgenesb (Softberry Inc., Mount Kisco, NY, US). The gene sequences were manually curated using NCBI's geneview and BioEdit. We extracted the genes transcribed in the same direction as $p l d A$ and used Fgenesb to find out which genes likely are co-regulated.

\section{In silico protein sequence analyses}

Structure-based MSAs were produced using the workflow described by Kuipers et al. [18]. This procedure uses core sequence elements (e.g. $\beta$-strands and $\alpha$-helices) to generate an initial profile. The sequences of all homologs (found with Blastp [48]) are aligned iteratively to the profile that is updated after each alignment round. The aligned sequences of the model and template were extracted from the final MSA (see Additional file 2) and used to construct the 3D structure model (see Fig. 2a).

\section{In silico protein entropy-variability analyses}

The MSA was used to develop an evolutionary model through EVA. The MSA and EVA analyses were performed as described $[16,18]$ using the YASARA/WHAT IF twinset [49-51]. EVA plots the entropy versus the variability to describe the variability pattern for every residue in the MSA. This plot contains five sectors that each holds residues with common structural and functional characteristic, as shown in Fig. 10 [19].

\section{EV-plot example}

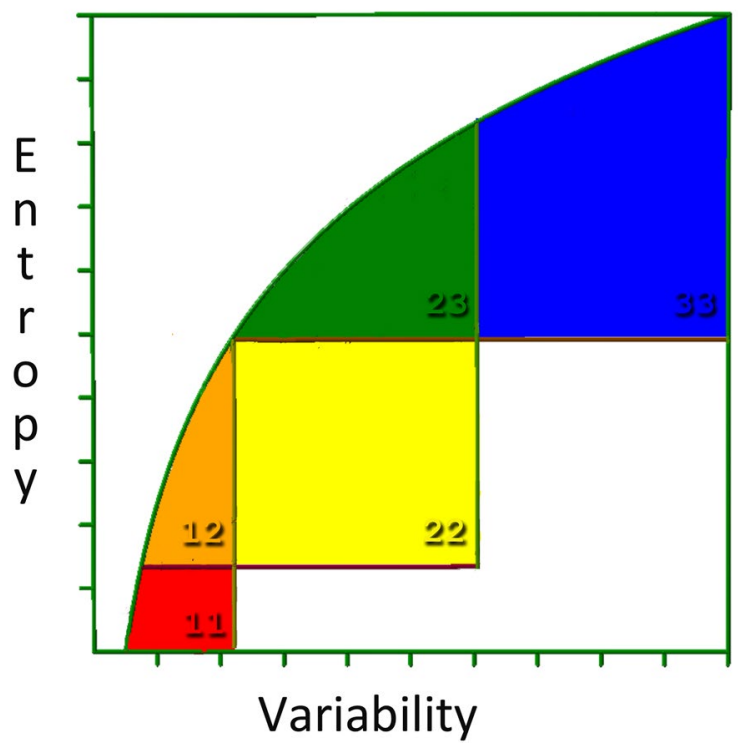

Fig. 10 EV-plot to explain the five different boxes found in EVA. The main active site residues are found in the box coloured red (box 11, low variability and low entropy). Residues supporting the active site are coloured orange (box 12, intermediate entropy and low variability). Yellow represents residues involved in communication between the main active site and regulatory sites (box 22, intermediate entropy and intermediate variability). The green area holds residues involved in regulation (box 23, high entropy and intermediate variability). Blue represents residues with no known function (box 33, high entropy and high variability). In an actual EV-plot, one will find crosses inside each box that represents the residues in the consensus sequence of the MSA

\section{OMPLA 3D structure modelling}

The $H$. pylori OMPLA model was built for the NCBI: AFR51731 sequence using the 1QD5 [15] (monomer PDB file downloaded from [http://www.rcsb.org] [52]) as template. The sequence alignment underlying the homology modelling was extracted from the aforementioned MSA. All waters, lipids, and crystallization additives were removed from the template file before modelling, and the remaining, reduced monomer was further subjected to the YASARA Clean function in the YASARA/WHAT IF twinset. The actual modelling was performed with the WHAT IF server [swift.cmbi.ru.nl/servers/html] because the sequence alignment was complicated and this server strictly follows the user-given alignment. The md_runmembranefast script in YASARA/WHAT IF twinset was used to optimize all 3D models. The very putative motif of the not-modelled insert was predicted by constructing the entire $H$. pylori OMPLA model automatically in YASARA/WHAT IF twinset, using the hm_build script. 


\section{D structure modelling of two genes in the pldA operon: $\mathrm{AmCl}$ and AmCll}

The two $\mathrm{Na}^{+}$-dependent channels of the SNF family (AmCI and AmCII; corresponding to the HP0497 and HP0498 genes in H. pylori strain 26695) homology models were constructed with YASARA/WHAT IF twinset, as described for $H$. pylori OMPLA. Both models were constructed using the same PDB file 4US3 as template. The alignments were extracted from a single large MSA that was generated as described below.

\section{In silico protein structure analyses}

All structure analyses were performed using the YASARA/WHAT IF twinset. Models and template structures were superposed using the MUSTANG pairwise protein structure aligner [53] as implemented in YASARA. The OMPLA pore was visualized with different substrates with molecular surfaces shown using YASARA/WHAT IF twinset. Pore sizes were estimated using WHAT IF (as implemented in the YASARA/ WHAT IF twinset), where solvent exclusion maps were produced for spherical probes with radius $\mathrm{P}$ using the surface map option in WHAT IF (srfmap) [49, 54]. PoreWalker was used to estimate possible pore paths (see Fig. 2 in Additional file 3) [55].

\section{Additional files}

Additional file 1. Detailed overview of H. pylori acid tolerance mechanism (the urea pathway).

Additional file 2. OMPLA multiple sequence alignment file.

Additional file 3. Homology modelling results.

Additional file 4. Residue numbering in E. coli and H. pylori sequences. structures, and models.

Additional file 5. H. pylori OMPLA variants survival in acidic environment.

\begin{abstract}
Abbreviations
aCA: a-carbonic anhydrase; AFLP: amplified fragment length polymorphism; AmCl: ammonium channel I; AmCll: ammonium channel II; COG: clusters of orthologous group; EVA: entropy-variability analyses; IM: inner membrane; MSA: multiple sequence alignment; OM: outer membrane; OMPLA: outer membrane phospholipase A; TLC: thin-layer chromatography.
\end{abstract}

\section{Authors' contributions}

HSV planned the study design and performed all the bioinformatics analyses; TT planned the study design and performed the experimental analyses; DC supervised the study; GV supervised the bioinformatics procedures and participated in planning the study design; GB supervised the study. All authors read and approved the final manuscript.

\section{Author details}

${ }^{1}$ Department of Clinical Molecular Biology (EpiGen), Division of Medicine, Akershus University Hospital and University of Oslo, PO box 28, 1478 Lørenskog, Norway. ${ }^{2}$ Norwegian Institute of Public Health, Box 4404, Nydalen, 0403 Oslo, Norway. ${ }^{3}$ Department of Community Medicine and Global Health, Faculty of Medicine, University of Oslo, P.O. Box 1130, Blindern, 0318 Oslo, Norway. ${ }^{4} \mathrm{CMBl}$, Radboudumc, 6525 GA Nijmegen, The Netherlands. ${ }^{5}$ Norwegian University of Life Sciences, PO Box 5003, 1430 Ås, Norway.

\section{Acknowledgements}

We thank Dr. Guillem Portella for computational support. Part of this work was presented in posters at the XXIst and XXIVth International Workshop on Helicobacter and related bacteria in chronic digestive inflammation $[56,57]$.

\section{Competing interests}

The authors declare that they have no competing interests.

\section{Availability of data and materials}

All data generated or analysed during this study are included in this published article and its Additional files 1, 2, 3, 4 and 5. The datasets used and/or analysed during the current study are available from the corresponding author upon request.

\section{Funding}

This research was supported by Grants from the Norwegian South-Eastern Regional Health Authority (Project Number 2007016).

\section{Publisher's Note}

Springer Nature remains neutral with regard to jurisdictional claims in published maps and institutional affiliations.

Received: 12 April 2017 Accepted: 8 June 2017

Published online: 12 June 2017

\section{References}

1. Lund P, Tramonti A, De Biase D. Coping with low pH: molecular strategies in neutralophilic bacteria. FEMS Microbiol Rev. 2014;38:1091-125.

2. Koebnik R, Locher KP, Van Gelder P. Structure and function of bacterial outer membrane proteins: barrels in a nutshell. Mol Microbiol. 2000;37:239-53.

3. Kong F, Singh RP. Disintegration of solid foods in human stomach. J Food Sci. 2008:73:R67-80

4. Menard A, Pere-Vedrenne C, Haesebrouck F, Flahou B. Gastric and enterohepatic Helicobacters other than Helicobacter pylori. Helicobacter. 2014;19(Suppl 1):59-67.

5. Mikkonen TP, Karenlampi RI, Hanninen ML. Phylogenetic analysis of gastric and enterohepatic Helicobacter species based on partial HSP60 gene sequences. Int J Syst Evol Microbiol. 2004;54:753-8.

6. Eun CS, Kim BK, Han DS, Kim SY, Kim KM, Choi BY, Song KS, Kim YS, Kim JF. Differences in gastric mucosal microbiota profiling in patients with chronic gastritis, intestinal metaplasia, and gastric cancer using pyrosequencing methods. Helicobacter. 2014;19:407-16.

7. Scott DR, Marcus EA, Wen Y, Oh J, Sachs G. Gene expression in vivo shows that Helicobacter pylori colonizes an acidic niche on the gastric surface. Proc Natl Acad Sci USA. 2007:104:7235-40.

8. Pflock M, Kennard S, Delany I, Scarlato V, Beier D. Acid-induced activation of the urease promoters is mediated directly by the ArsRS two-component system of Helicobacter pylori. Infect Immun. 2005;73:6437-45

9. Bishop RE. Structural biology of membrane-intrinsic $\beta$-barrel enzymes: sentinels of the bacterial outer membrane. Biochim Biophys Acta. 2008:1778:1881-96

10. Dorrell N, Martino MC, Stabler RA, Ward SJ, Zhang ZW, McColm AA, Farthing MJ, Wren BW. Characterization of Helicobacter pylori PIdA, a phospholipase with a role in colonization of the gastric mucosa. Gastroenterology. 1999;117:1098-104.

11. Istivan TS, Coloe PJ. Phospholipase A in Gram-negative bacteria and its role in pathogenesis. Microbiology. 2006;152:1263-74.

12. Tannaes T, Dekker N, Bukholm G, Bijlsma JJ, Appelmelk BJ. Phase variation in the Helicobacter pylori phospholipase A gene and its role in acid adaptation. Infect Immun. 2001;69:7334-40.

13. Darmon E, Leach DR. Bacterial genome instability. Microbiol Mol Biol Rev. 2014;78:1-39.

14. Vollan HS, Tannaes T, Yamaoka Y, Bukholm G. In silico evolutionary analysis of Helicobacter pylori outer membrane phospholipase A (OMPLA). BMC Microbiol. 2012;12:206. 
15. Snijder HJ, Ubarretxena-Belandia I, Blaauw M, Kalk KH, Verheij HM, Egmond MR, Dekker N, Dijkstra BW. Structural evidence for dimerizationregulated activation of an integral membrane phospholipase. Nature. 1999:401:717-21.

16. Vollan HS, Tannæs T, Vriend G, Bukholm G. In silico structure and sequence analysis of bacterial porins and specific diffusion channels for hydrophilic molecules: conservation, multimericity and multifunctionality. IJMS. 2016;17:599.

17. Tannæs T, Dekker N, Bukholm G, Bijlsma JJE, Appelmelk BJ. Phase variation in the Helicobacter pylori phospholipase A gene and its role in acid adaptation. Infect Immun. 2001:69:7334-40.

18. Kuipers RK, Joosten HJ, Van Berkel WJ, Leferink NG, Rooijen E, Ittmann E, Van Zimmeren F, Jochens H, Bornscheuer U, Vriend G, et al. 3DM: systematic analysis of heterogeneous superfamily data to discover protein functionalities. Proteins. 2010;78:2101-13.

19. Oliveira L, Paiva PB, Paiva AC, Vriend G. Identification of functionally conserved residues with the use of entropy-variability plots. Proteins. 2003:52:544-52.

20. Marti-Renom MA, Madhusudhan MS, Eswar N, Pieper U, Shen M, Sali A, Fiser A, Mirkovic N, John B, Stuart A. Modeling protein structure from its sequence. In: current protocols in bioinformatics. New York: Wiley; 2002.

21. Kusters JG, van Vliet AHM, Kuipers EJ. Pathogenesis of Helicobacter pylori infection. Clin Microbiol Rev. 2006;19:449-90.

22. O'Toole PW, Snelling WJ, Canchaya C, Forde BM, Hardie KR, Josenhans C, Graham R, McMullan G, Parkhill J, Belda E, Bentley SD. Comparative genomics and proteomics of Helicobacter mustelae, an ulcerogenic and carcinogenic gastric pathogen. BMC Genom. 2010;11:164.

23. Flahou B, Haesebrouck F, Smet A, Yonezawa H, Osaki T, Kamiya S. Gastric and enterohepatic non-Helicobacter pylori Helicobacters. Helicobacter. 2013;18(Suppl 1):66-72

24. Cáceres-Delpiano J, Teneb J, Mansilla R, García A, Salas-Burgos A. Variations in periplasmic loop interactions determine the $\mathrm{pH}$-dependent activity of the hexameric urea transporter Urel from Helicobacter pylori: a molecular dynamics study. BMC Struct Biol. 2015;15:11.

25. Mari SA, Koster S, Bippes CA, Yildiz O, Kuhlbrandt W, Muller DJ. pHinduced conformational change of the $\beta$-barrel-forming protein OmpG reconstituted into native E. coli lipids. J Mol Biol. 2010;396:610-6.

26. Basle A, Qutub R, Mehrazin M, Wibbenmeyer J, Delcour AH, Bayley H. Deletions of single extracellular loops affect $\mathrm{pH}$ sensitivity, but not voltage dependence, of the Escherichia coli porin OmpF. Protein Eng Des Sel. 2004; 17:665-72.

27. Li CC, Ho TY, Kao CH, Wu SL, Liang JA, Hsiang CY. Conserved charged amino acid residues in the extracellular region of sodium/iodide symporter are critical for iodide transport activity. J Biomed Sci. 2010;17:89.

28. Liu N, Delcour AH. Inhibitory effect of acidic $\mathrm{pH}$ on $\mathrm{OmpC}$ porin: wildtype and mutant studies. FEBS Lett. 1998:434:160-4.

29. Kadurin I, Huber S, Grunder S. A single conserved proline residue determines the membrane topology of stomatin. Biochem J. 2009;418:587-94.

30. Deber CM, Therien AG. Putting the $\beta$-breaks on membrane protein misfolding. Nat Struct Biol. 2002;9:318-9.

31. Dutton RJ, Boyd D, Berkmen M, Beckwith J. Bacterial species exhibit diversity in their mechanisms and capacity for protein disulfide bond formation. Proc Natl Acad Sci USA. 2008;105:11933-8.

32. Tie JK, Jin DY, Stafford DW. Conserved loop cysteines of vitamin K epoxide reductase complex subunit 1-like 1 (VKORC1L1) are involved in its active site regeneration. J Biol Chem. 2014;289:9396-407.

33. Wang $X$, Jiang F, Zheng J, Chen L, Dong J, Sun L, Zhu Y, Liu B, Yang J, Yang G, Jin Q. The outer membrane phospholipase A is essential for membrane integrity and type III secretion in Shigella flexneri. Open Biol. 2016;6(9):160073.

34. Wheatley M, Wootten D, Conner MT, Simms J, Kendrick R, Logan RT, Poyner DR, Barwell J. Lifting the lid on GPCRs: the role of extracellular loops. Br J Pharmacol. 2012;165:1688-703.

35. Price MN, Arkin AP, Alm EJ. The life-cycle of operons. PLoS Genet. 2006;2:e96.
36. Taboada B, Ciria R, Martinez-Guerrero CE, Merino E. ProOpDB: prokaryotic operon database. Nucleic Acids Res. 2012;40:D627-31.

37. Tatusov RL, Galperin MY, Natale DA, Koonin EV. The COG database: a tool for genome-scale analysis of protein functions and evolution. Nucleic Acids Res. 2000;28:33-6.

38. Bala PA, Foster J, Carvelli L, Henry LK. SLC6 transporters: structure, function, regulation, disease association and therapeutics. Mol Asp Med. 2013;34:197-219.

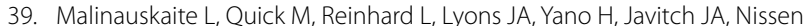
P. A mechanism for intracellular release of $\mathrm{Na}^{+}$by neurotransmitter/ sodium symporters. Nat Struct Mol Biol. 2014;21:1006-12.

40. Singh SK, Pal A. Biophysical approaches to the study of LeuT, a prokaryotic homolog of neurotransmitter sodium symporters. Methods Enzymol. 2015;557:167-98

41. Saier Lab Bioinformatics Group: 2.A.22 the neurotransmitter: sodium symporter (NSS) family. http://www.tcdb.org/search/result.php?tc=2.A.22. Accessed Mar 2017.

42. Scott DR, Marcus EA, Wen Y, Singh S, Feng J, Sachs G. Cytoplasmic histidine kinase (HP0244)-regulated assembly of urease with Urel, a channel for urea and its metabolites, $\mathrm{CO}_{2}, \mathrm{NH}_{3}$, and $\mathrm{NH}_{4}{ }^{+}$, is necessary for acid survival of Helicobacter pylori. J Bacteriol. 2010;192:94-103.

43. Stingl K, Uhlemann EM, Schmid R, Altendorf K, Bakker EP. Energetics of Helicobacter pylori and its implications for the mechanism of ureasedependent acid tolerance at pH 1. J Bacteriol. 2002;184:3053-60.

44. Fischer F, De Reuse H. Adaptation of Helicobacter pylori metabolism to persistent gastric colonization. In: Backert S, Yamaoka Y, editors. Helicobacter pylori research: from bench to bedside. Tokyo: Springer; 2016. p. 29-56.

45. Huang JY, Goers Sweeney E, Guillemin K, Amieva MR. Multiple acid sensors control Helicobacter pylori colonization of the stomach. PLoS Pathog. 2017;13:e1006118.

46. Marcus EA, Scott DR. Gastric colonization by H. pylori. In: Kim N, editor. Helicobacter pylori. Singapore: Springer; 2016. p. 23-34 (Part II).

47. Tannaes T, Bukholm G. Cholesteryl-6-O-acyl-alpha-D-glucopyranoside of Helicobacter pylori relate to relative lysophospholipid content. FEMS Microbiol Lett. 2005;244:117-20.

48. Johnson M, Zaretskaya I, Raytselis Y, Merezhuk Y, McGinnis S, Madden TL. NCBI BLAST: a better web interface. Nucleic Acids Res. 2008;36:W5-9.

49. Vriend G. WHAT IF: a molecular modeling and drug design program. J Mol Graph. 1990;8(52-56):29.

50. Krieger E, Koraimann G, Vriend G. Increasing the precision of comparative models with YASARA NOVA-a self-parameterizing force field. Proteins. 2002;47:393-402.

51. Krieger E, Vriend G. New ways to boost molecular dynamics simulations. J Comput Chem. 2015;36:996-1007.

52. Rose PW, Prlic A, Altunkaya A, Bi C, Bradley AR, Christie CH, Costanzo LD, Duarte JM, Dutta S, Feng Z, et al. The RCSB protein data bank: integrative view of protein, gene and 3D structural information. Nucleic Acids Res. 2017:45:D271-81.

53. Konagurthu AS, Whisstock JC, Stuckey PJ, Lesk AM. MUSTANG: a multiple structural alignment algorithm. Proteins. 2006:64:559-74.

54. Voorintholt R, Kosters MT, Vegter G, Vriend G, Hol WG. A very fast program for visualizing protein surfaces, channels and cavities. J Mol Graph. 1989;7:243-5.

55. Pellegrini-Calace M, Maiwald T, Thornton JM. PoreWalker: a novel tool for the identification and characterization of channels in transmembrane proteins from their three-dimensional structure. PLoS Comput Biol. 2009; 5:e1000440.

56. Esbensen Y, Vollan HS, Tannaes TM. A functional Outer membrane phospholipase $A(O M P L A)$ is required for survival of Helicobacter pylori at $\mathrm{pH}$ 3.5 [abstract]. Helicobacter. 2011;16(suppl 1):97-8.

57. Vollan HS, Portella G, Tannaes T, de Groot BL, Vriend G, Bukholm G. A homology model of H. pylori OMPLA [abstract]. Helicobacter. 2008;13:423. 